\title{
Complex techniques of eyelid reconstruction following extensive basal cell carcinoma resection
}

\author{
Alexander C. Rokohl ${ }^{1}$, Adam Kopecky ${ }^{2,3}$, Philomena A. Wawer Matos ${ }^{1}$, Yongwei Guo ${ }^{4}$, \\ Vinodh Kakkassery ${ }^{5}$, Ludwig M. Heindl ${ }^{1,6}$ \\ ${ }^{1}$ Department of Ophthalmology, University of Cologne, Faculty of Medicine and University Hospital of Cologne, Cologne, Germany; \\ ${ }^{2}$ Ophthalmology Clinic, University Hospital Ostrava, Ostrava, Czech Republic, University Ostrava, Ostrava, Czech Republic; ${ }^{3}$ Department of \\ Craniofacial Surgery, University of Ostrava, Ostrava, Czech Republic; ${ }^{4}$ Eye Center, Second Affiliated Hospital, School of Medicine, Zhejiang \\ University, Hangzhou, China; ${ }^{5}$ Department of Ophthalmology, University of Lübeck, Lübeck, Germany; ${ }^{6}$ Center for Integrated Oncology (CIO) \\ Aachen-Cologne-Bonn-Duesseldorf, Cologne, Germany \\ Contributions: (I) Conception and design: AC Rokohl, A Kopecky, LM Heindl; (II) Administrative support: AC Rokohl, A Kopecky, V Kakkassery; \\ (III) Provision of study materials or patients: A Kopecky, Y Guo, PA Wawer Matos, AC Rokohl; (IV) Collection and assembly of data: All authors; (V) \\ Data analysis and interpretation: All authors; (VI) Manuscript writing: All authors; (VII) Final approval of manuscript: All authors. \\ Correspondence to: Dr. med. Alexander C. Rokohl, MD. Department of Ophthalmology, University of Cologne, Faculty of Medicine and University, \\ Hospital of Cologne, Kerpenerstr. 62, 50937 Cologne, Germany. Email: alexander.rokohl@uk-koeln.de.
}

\begin{abstract}
Basal cell carcinoma (BCC) is one of the most common malignant tumors overall and even the most common malignant tumors in ophthalmology. In most cases, surgical resection followed by an ophthalmoplastic reconstruction is the current gold standard for the treatment of periocular BCC. Histopathologic analysis can be performed both as a frozen section examination, Mohs micrographic surgery, or as a rapid embedding analysis, depending on the surgeon's preference or the in-house standard. A histopathologic workup is essential not only for confirming the diagnosis and determining resection status but especially for identifying infiltrating growing subtypes, as this also influences postoperative follow-up and prognosis. A wide range of various reconstruction methods allow individualized defect coverage with mostly good cosmetically and functionally results. The basic principle is to restore the anatomy with an anterior and posterior eyelid lamella. The selection of the appropriate technique depends not only on the vertical and horizontal defect size, defect localization, or potential eyelid edge involvement but also significantly on the patient's age, available tissue (e.g., skin), the patient's preference, and especially the surgeon's experience. For smaller, partial, or penetrating defects, direct wound closure can be performed. However, for greater defects more complex reconstruction techniques including Tenzel's rotational plasty, Hughes flap, CutlerBeard plastic, Mustardé lid Switch flap, tarsomarginal grafts according to Huebner, or V-Y glabella flap are necessary, dependently on the size and the location of the defect. However, in advanced findings with infiltration of the orbit, orbital exenteration is unavoidable in some cases. Postoperative regular follow-up is essential to identify potential complications in an early stage.
\end{abstract}

Keywords: Basal cell carcinoma (BCC); Hughes flap; Cutler-Beard; eyelid reconstruction

Received: 04 February 2021; Accepted: 25 April 2021; Published: 10 June 2021.

doi: $10.21037 /$ fomm-21-11

View this article at: http://dx.doi.org/10.21037/fomm-21-11

\section{Introduction}

Basal cell carcinoma (BCC) is one of the most common malignant tumors overall and even the most common malignant tumors in ophthalmology (1-6). In Western
Europe, the annual incidence is approximately 2,000 per $1,000,000$ population (3-6). Although the average age is over 60 years, especially in younger people the incidence is increasing in the last decades $(1,2,4-6)$. BCCs usually 
present as slow-growing, painless skin lesions $(1,4-7)$. BCCs are mostly waxy and shiny, indurated lesions with a pearly margin, surrounded by telangiectasias. Sometimes central ulceration is visible (1,4-7). For most cases, the gold standard for periocular BCC is the complete tumor excision with histopathologic control of the tumor margins ( $\mathrm{pR} 0$ resection) (1,2,4-12). Various patient conditions and tumor locations, as well as the different sizes of BCC, require diverse ophthalmoplastic reconstructive procedures (5). Therefore, each ophthalmoplastic surgeon should be trained in a wide range of reconstructive techniques (5).

This article aims to provide an overview of reconstruction procedures and to highlight some of the most complex ophthalmoplastic reconstructive techniques.

\section{Tumor excision and histopathological analysis}

Local excision should always be individualized according to the clinical findings $(1,4-7,13)$. In BCC of the eyelids, a safety margin is not required since only histopathologically confirmed R0 resection improves the prognosis $(1,4-6,14,15)$. Therefore, no safety margin is necessary for BCC of the eyelids, because preserved healthy eyelid tissue may be crucial for subsequent functional reconstruction (5). Therefore, surgical resection should always excise as much tissue as necessary to achieve R0 resection but remove as little healthy tissue as possible to ensure the best possible reconstruction with a good aesthetic outcome $(5,13)$. Therefore, close cooperation with a center for pathology is necessary (5). After tumor excision, pathologists analyze the tissue borders - in addition to a central incision to confirm the diagnosis - serially from the margins in $4 \mu \mathrm{m}$ steps. If the first three sections show no more tumor cells, an R0 resection is assumed (5). While the recurrence rate for R0 resection is approximately $30 \%(1,4-6,13-15)$, in contrast, the risk of recurrence increases significantly for R1 resection $(4,5,15)$. Histopathologic analysis can be performed both as a frozen section examination, Mohs micrographic surgery, or as a rapid embedding analysis, depending on the surgeon's preference or the in-house standard (5).

In the frozen section examination, the excised tissue is removed and immediately provided native, i.e., without formalin, to the pathologist for intraoperative processing and evaluation (5). After macroscopic examination by the pathologist, the specimen is cut on the cryostat and stained in a rapid procedure (5). After approx. 15-40 minutes (depending on the type and quantity of the samples sent in), the surgeon is already informed of the examination result by telephone (5). If tumor-free resection margins are present on all sides, as confirmed by the histopathologist (pR0 resection), ophthalmoplastic reconstruction can be started directly (5). In case of a pR1 or pR2 status (histologically or macroscopically not tumor-free resection margins), further resection should be performed (5). Thereafter, a repeat frozen section examination of the resected tissue should be performed (5). This should be done as often as necessary until a pR0 status is obtained (5). However, frozen section preparations have a certain loss of quality compared to conventionally prepared histology preparations so that a final diagnosis follows only after conventional tissue processing with formalin fixation and regular staining (5). Compared to rapid embedding, frozen section analysis has the great advantage that tumor excision and ophthalmoplastic reconstruction can be performed in one session (5).

For the rapid embedding, mostly a tissue sample fixed in formalin is processed in a special, time-reduced procedure (5). Results are normally available the next day (5). Pure processing time is usually about 3-4 hours (5). The advantage of rapid embedding is a better and more reliable assessment of the incision margin due to less loss of quality (5). Furthermore, a first histological diagnosis is already available at the time of reconstruction (5). The disadvantage of rapid embedding is the multi-stage procedure, i.e., patients are operated on in at least two sessions on two different days (5). If resection is necessary, the number of sessions required increases again (5). However, it must be noted that there is no randomized study comparing frozen sectioning with frozen embedding for incision margin diagnosis in periocular BCC concerning their recurrence rates (5).

In Mohs micrographic surgery, the histological processing and surgery take place only on one day including wound closing after histopathologically confirmed R0 resection. However, the total procedure is time-consuming and usually lasts mostly 4 hours and longer. In Mohs micrographic surgery, the excision margins are examined by a rapid embedding technique. This technique allows that horizontal sections are cut involving all deep and radial excision margins. If any tumor cells are visible in these sections, it means that the excision is incomplete, and the patient requires a further resection. During Mohs surgery, a mapping process and color-coding system are mostly used for a precise localizing of any remaining cancer cells.

Overall, a histopathologic workup is essential not only for confirming the diagnosis and determining resection 
A

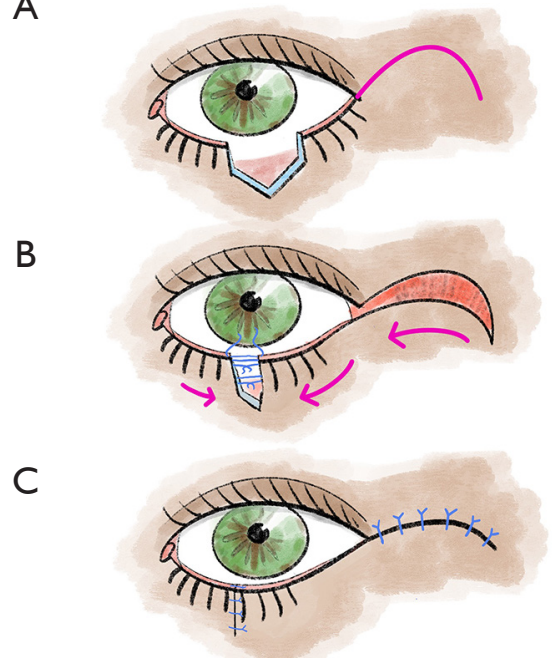

Figure 1 Tenzel's rotational plasty. A semicircular incision is made at the lateral canthus, including the skin and the orbicularis oculi muscle (A). In addition, a lateral cantholysis is performed. The tissue is tissue is mobilized medially, and closure of the lid defect is performed (B). The defect created due to flap preparation is closed with a suture $(\mathrm{C})$.

status but especially for identifying infiltrating growing subtypes, as this also influences postoperative follow-up and prognosis $(4-7,16)$. For further differentiation from other tumor entities, such as squamous cell carcinoma, further immunohistochemical examinations, such as epithelial cell adhesion molecule (EpCAM) and for epithelial membrane antigen (EMA), can be added after histologic workup, if necessary $(4,5)$.

\section{Reconstruction techniques of the eyelids}

After a successful pR0 resection, different reconstruction techniques of the eyelids are needed depending on the defect size and location $(1,2,4-7,12,13,17)$. The basic principle is to restore the anatomy with an anterior and posterior eyelid lamella $(4,5,13)$. The selection of the appropriate technique depends not only on the vertical and horizontal defect size, defect localization, or potential eyelid edge involvement but also significantly on the patient's age, available tissue (e.g., skin), the patient's preference, and especially the surgeon's experience $(4,5,13,18)$.

For smaller, partial, or penetrating defects, direct wound closure can be performed, whereas for larger defects, various displacement flaps, hereafter referred to as flaps for simplicity, and free grafts are used $(1,4-7,13,17,18)$. In general, when reconstructing the anterior lid flap with a free skin graft, only one flap and not a second free graft may be used for the posterior lid flap $(4,5,13,18)$. In the case of reconstruction of the posterior lamella with a free graft, the anterior lamella of the eyelid should then be treated with a flap and should not be performed as a second free graft $(5,13,18)$. The tissue used may be from the ipsilateral or contralateral eye or other body regions. In addition, artificial or even foreign supporting tissue can be used $(4,5,13,18)$.

Tenzel's rotational plasty (Figure 1) is suitable for reconstructions of both the lower and upper eyelids $(5,13)$. For example, the Tenzel flap, a semicircular muscle-skin flap is well suited for large defects but less than $75 \%$ of the width of the eyelid $(5,13)$. A semicircular incision is made at the lateral canthus, including the skin and the orbicularis oculi muscle. In addition, a lateral cantholysis is performed. Now the lid tissue is mobilized medially, and closure of the lid defect is performed. Then, the defect created due to flap preparation is closed with a suture $(5,13)$.

Although larger defects of the upper eyelid are a typical indication for rotational plastic surgery according to Tenzel, these penetrating defects, especially if they exceed $75 \%$ of the eyelid width, can also be treated with Cutler-Beard plastic surgery $(5,13,17)$. In our experience, this provides good functional and also cosmetic results $(5,13)$. Overall, Cutler-Beard plastic surgery is a relatively low-complication alternative to the various rotational and displacement flap procedures and can therefore be used very well for all central lid defects as well as for larger medial and lateral defects $(5,13)$. Major contraindications to Cutler-Beard plastic include functional one-eyedness on the affected side or the patient's desire for a procedure that does not require a second surgery $(5,13,19)$. Cutler-Beard plastic involves dissection of a cutaneomusculoconjunctival flap from the ipsilateral lower eyelid $(5,13)$ (Figure 2). Care must be taken to preserve an intact lower lid bridge with an intact lid margin, intact tarsus, and intact inferior tarsal artery $(5,13)$. A large zone at the lower eyelid margin and an intact inferior tarsal artery reduce the risk of subsequent complications such as lower eyelid necrosis $(5,13)$. This cutaneomusculoconjunctival flap from the lower lid is then pulled cranially posterior to the lower lid bridge $(5,13)$. Then all three layers, one at a time, are sutured into the defect area of the upper eyelid $(5,13)$. If the defect is larger than three-quarters of the upper eyelid width, additional tissue can be used for stabilization $(5,13)$. For example, this 


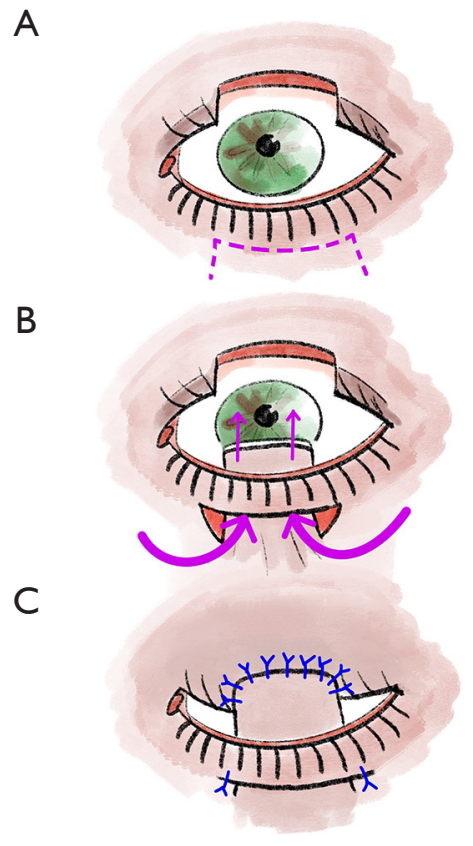

Figure 2 Cutler-Beard plastic. Dissection of a cutaneomusculoconjunctival flap from the ipsilateral lower eyelid with an intact lower lid bridge with an intact lid margin, intact tarsus, and intact inferior tarsal artery is planned (A). The cutaneomusculoconjunctival flap from the lower lid is then pulled cranially posterior to the lower lid bridge (B). All three layers, one at a time, are sutured into the defect area of the upper eyelid (C).

tissue can come from the donor sclera or the tarsus of the contralateral eyelid $(5,13)$. Without additional stabilizing tissue, the risk of various postoperative eyelid malpositions, such as upper eyelid ectropion, increases $(5,13)$. Usually, after 4 to 6 weeks, the flap pedicle is cut and refixed into the lower eyelid defect in a layered fashion $(5,13,17)$. If necessary, additional conjunctiva can be sutured to the skin over the new upper eyelid edge $(5,13)$.

Eyelid defects in the middle-upper lid can alternatively be treated with a Mustarde Lid Switch (cheek) rotation flap (Figure 3) $(5,13)$. This rotation flap from the lower eyelid, which must not exceed one-third of the eyelid width, is first prepared as a pedicled flap $(5,13)$. This ensures an optimal blood supply $(5,13)$. Afterward, this is rotated upwards $(5,13)$. The resulting lower lid defect is then sutured directly, and the upper lid can be reconstructed with the rotated flap and with a semicircular flap $(5,13)$. The pedicle is then later separated in a second operation $(5,13,20,21)$. The major advantage of this reconstruction technique is
A

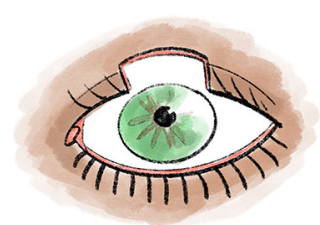

B

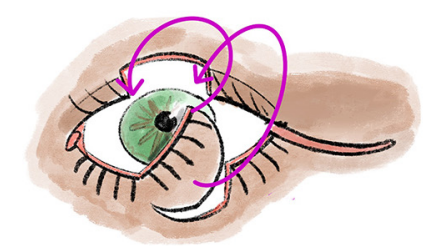

C

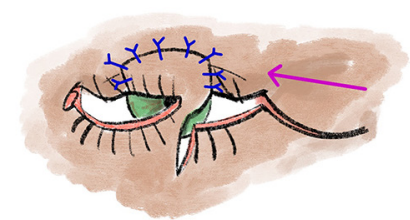

D

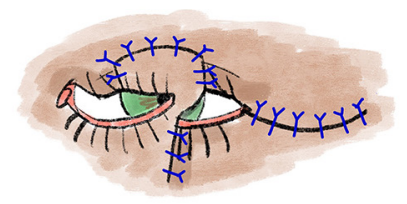

Figure 3 Mustardé lid switch flap. This technique is suitable for the upper eyelid defects (A). Rotation flap from the lower eyelid, which must not exceed one third of the eyelid width, is firstly prepared as a pedicled flap (B). Afterward, this flap is rotated upwards (C). The resulting lower lid defect is then sutured directly, and the upper lid can be reconstructed with the rotated flap and with a semicircular flap (D).

that all layers of the eyelid can be directly reconstructed in a single step $(5,13)$. However, because deformities of the lower eyelid are more common with this reconstruction technique, Cutler-Beard plasty is usually preferred both in clinical practice and in the literature $(5,13)$.

The Hughes flap is a pedicled displacement flap made from the conjunctiva and tarsus of the upper eyelid and is used to reconstruct the lower eyelid $(5,13)$ (Figure 4). Since Hughes plastic surgery achieves very good cosmetic and functional results, it is one of the most important basic techniques in ophthalmoplastic surgery $(5,13)$. It is an established procedure for lower eyelid reconstruction, especially for central lower eyelid defects with medial and lateral residual tarsus $(5,13,22)$. In principle, the displacement flap can also be prepared together with the Müller muscle, but the Müller muscle part should be prepared away from the conjunctival pedicle as far as 
A

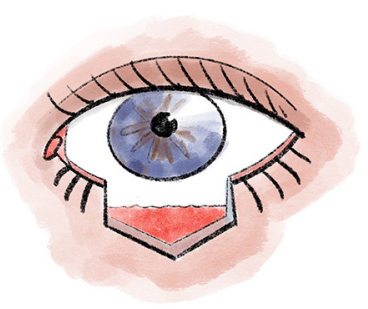

B

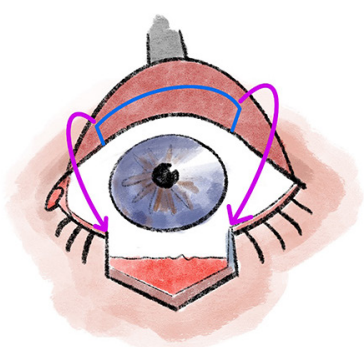

C

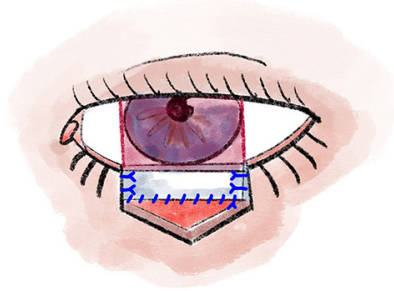

Figure 4 Hughes flap. Hughes flap is suitable for defects of the lower eyelid (A). A pedicled displacement flap made from the conjunctiva and tarsus of the upper eyelid is prepared and it dragged to the defect of the lower eyelid (B). The flap is secured in its place with suture, connected to surrounding tarsus and conjunctiva (C).

possible, otherwise, there is an increased risk of wound dehiscence due to muscle traction $(5,13)$.

To maintain good stability and adequate function of the upper lid, tarsal preparation should be performed at least $4 \mathrm{~mm}$ from the lid margin $(5,13)$. At the end of the preparation, the tarsal transponate is only attached to a conjunctival bridge $(5,13)$. This transponate is then sutured into the defect area of the lower lid $(5,13)$. For this purpose, first, the long edge of the transponate is connected with tarsal or fornix conjunctiva $(5,13)$. Then the lateral margins are sutured in, and good fixation (tarsus to tarsus or tarsus to periosteum) is crucial here $(5,13)$. In most cases, the anterior lamella must also be reconstructed with a free graft $(5,13)$. After the flap has healed for approximately 3-4 weeks, the Hughes plastic is opened $(5,13)$.

Tarsomarginal grafts according to Huebner can be used to reconstruct the upper eyelid as well as the lower eyelid
$(5,13,23)$. To cover, for example, a small lower eyelid defect with a tarsomarginal graft, a subciliary incision is first made in the lower eyelid of the healthy eye, and skin and muscle are split off from the tarsus underneath, followed by cutting out a tarsal shield with eyelashes and fitting it into the defect of the diseased eyelid $(5,23)$ (Figure 5). Then, a pivot flap is dissected from the diseased eye from the upper eyelid $(5,23)$. The skin remnant temporal from the eyelid defect is dissected off and kept to cover secondary skin defects in the upper eyelid area $(5,23)$. The tarsal defect is then sutured at the removal site and the lower eyelid skin is sutured to the eyelid edge in a gathered fashion $(5,23)$. In the diseased eye, the pivot flap is sutured over the tarsomarginal graft $(5,23)$. Hübner postulates that the main advantage of free tarsomarginal grafts is that the skin flap can contribute to the blood circulation of the grafts, thus reducing necrosis $(5,23)$. Furthermore, in this form of eyelid reconstruction, the muscle tissue most at risk of necrosis is not co-grafted, and for this reason alone, better healing can be expected $(5,23)$. Another special feature of the tarsomarginal graft described by Hübner is that several grafts can be fitted side by side $(5,23)$. This seems to be a significant advantage compared to other methods $(5,23)$. Thus, the tarsomarginal graft offers itself as a universal method for the reconstruction of both upper and lower eyelid defects of any size $(5,23)$. However, the advantage of preserving all eyelashes in the reconstruction area, as described by Hübner, must be partially renounced in large defects $(5,23)$. However, the patient must also be included in the consideration of tarsomarginal grafts versus Hughes or Cutler-Beard bridge flap surgery, as many patients are afraid of surgery on the healthy contralateral eye, as is the case with tarsomarginal grafts $(5,13)$.

For tumors at the inner corner of the eye that also deeply infiltrate the musculature, the V-Y glabella flap is the reconstruction technique of choice $(5,24)$ (Figure 6). For this displacement flap, first, draw an inverted "V" at the center of the forehead, one leg should reach the lateral edge of the defect $(5,24)$. The other leg should extend to the medial end of the opposite eyebrow $(5,24)$. The size of the flap should be chosen to allow tension-free coverage of the defect $(5,24)$. Then the flap is undermined in the subcutaneous fat tissue $(5,24)$. The pivot point of the flap is the bridge of the nose (24). When the position of the flap is clear, the flap can be fixed by a non-absorbable suture from the undersurface to the defect $(5,24)$. Now undermine the margins at the tip of the inverted $\mathrm{V}$ to be able to adapt the margins without tension by single button sutures up to above the eyebrows 

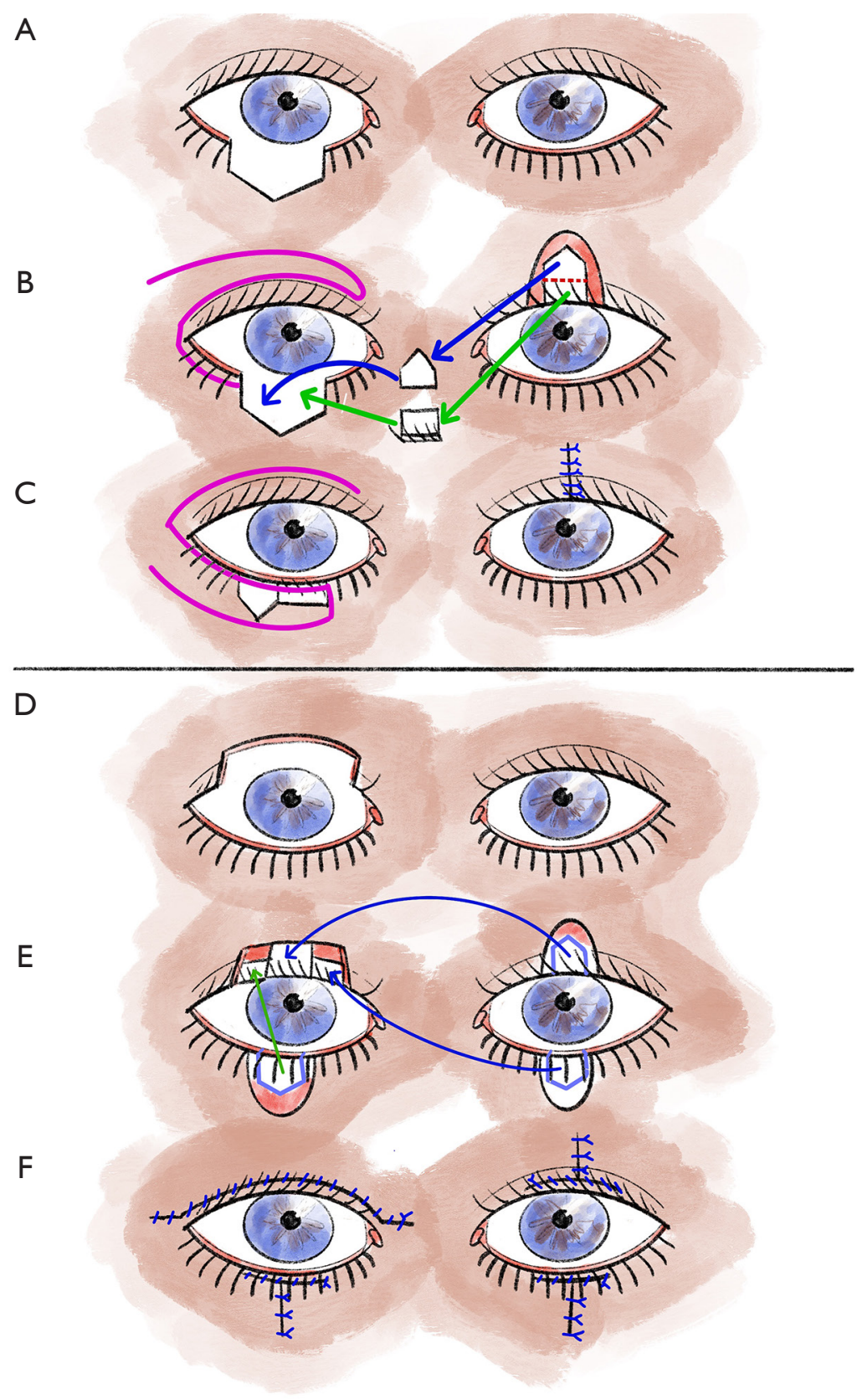

Figure 5 Tarsomarginal grafts according to Hübner. These grafts can be used to reconstruct the upper eyelid as well as the lower eyelid (A). Possible reconstruction of the lower eyelid defect using split tarsal graft from contralateral eyelid (B). The anterior lamella defect is covered with musculocutaneous rotational flap (C). Possible reconstruction of upper eyelid defect using tarsomarginal graft from all remaining eyelids (D-F).

$(5,24)$. Now knot the prefabricated suture on the inner side of the flap $(5,24)$. This is especially to mark and restore the contour of the medial lid angle $(5,24)$. After marking the excess tissue on the flap, it is cut off $(5,24)$. If necessary, compression folds can be compensated by relief incisions or wedge-shaped excision $(5,24)$. The flap is sutured in place with absorbable subcutaneous and non-absorbable cutaneous sutures $(5,24)$. After one week, the cutaneous 
A

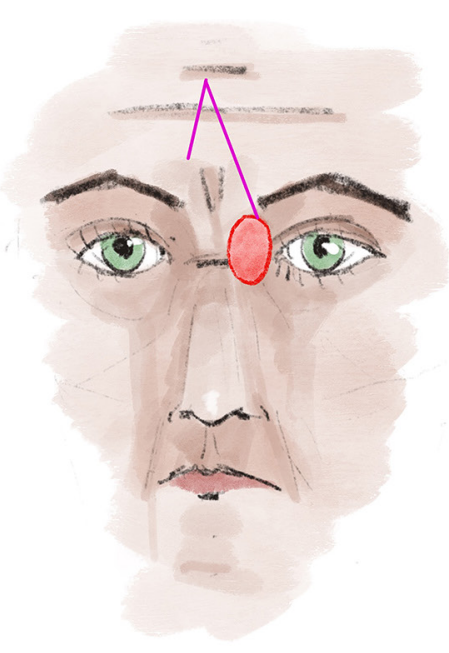

C

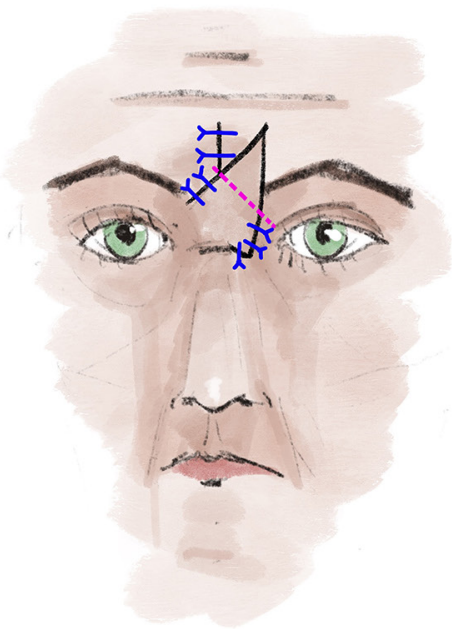

B

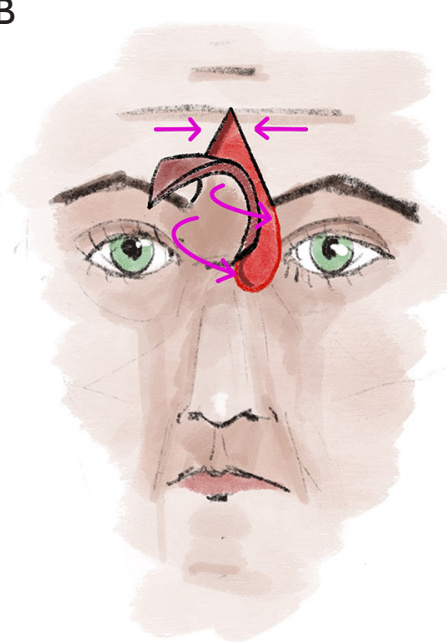

D

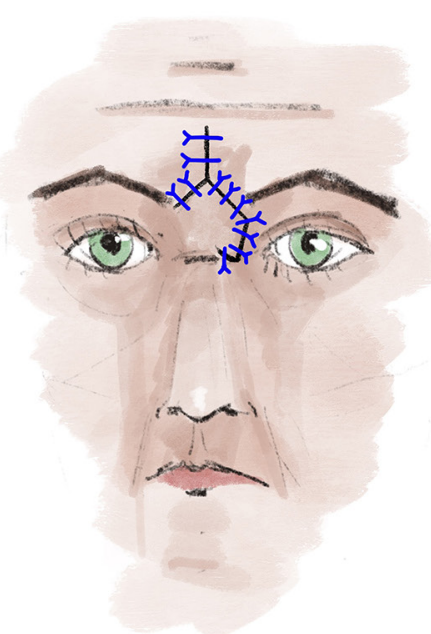

Figure $6 \mathrm{~V}-\mathrm{Y}$ flap. An inverted "V" at the center of the forehead is drawn, one leg reaches the lateral edge of the defect (A). The flap is undermined and mobilized (B). The flap is fixed to its new position without any tension (C). The excess tissue is marked and cut off. The suture of the flap is finished (D).

sutures can be removed $(5,24)$. The glabellar flap can also be combined with Cutler-Beard plastic surgery if the upper eyelid also shows a larger defect $(5,24)$. If the lower eyelid is also affected, a transconjunctival flap according to Hughes can also be used $(5,24)$. As alternatives for covering smaller defects in the medial lid angle, transnasal flaps $(5,25)$ or myocutaneous flaps from the bridge of the nose show good cosmetic results $(5,24,26)$.

In advanced findings with infiltration of the orbit, orbital exenteration is unavoidable in some cases (5). The defect can then be covered, for example, with temporalis flaps or with split skin (e.g., from the thigh) (5). Subsequent prosthetic treatment with an epithesis is possible both with and without magnetic pin implantation in the orbital bone $(5,27,28)$.

\section{Postoperative complications}

Occasionally, eyelid edge dehiscence or wound dehiscence may occur if the wound tension is too high or if the wound healing is disturbed (5). Larger dehiscences can be treated by scarce wound regeneration or minimal wedge excision and re-suturing (5). Smaller lower eyelid dehiscences after wedge excision, on the other hand, can be left to heal spontaneously, as far as the wetting situation allows (5).

With some techniques such as Hughes plastic, scar- 
induced upper eyelid retraction can occur, which is usually corrected without problems using scar solution (5). Other eyelid malpositions, hypertrophic scars, retractions, and asymmetries can be surgically repaired if necessary, during further treatment, preferably after primary scar healing is complete (5). Both necrosis and infection are rather rare complications if the procedure is performed correctly (5). Further complications include bleeding from the site of surgery, bleeding into the wound (hematoma) from surrounding tissue, as well as pain or tenderness in the area where the skin was removed.

\section{Local postoperative tumor follow-up}

Local follow-up should be performed in the area of the operated area but also especially in the area of the nonoperated, other exposure sites (other eyelids, face, scars) (5). Follow-up examinations after R0 resection should initially be performed quarterly to semiannually for the first 3 years after surgery, and annually thereafter $(1,5,7)$.

\section{Conclusions for the daily practice}

The highest priority for periocular BCC is complete, histopathologically controlled tumor excision (pR0). In this case, histopathologic workup can be performed by rapid embedding or intraoperatively by frozen section. A variety of reconstruction methods allow for an individually adapted as well as in most cases cosmetically and functionally appealing defect coverage. Postoperative regular tumor follow-up is essential.

\section{Acknowledgments}

Funding: None.

\section{Footnote}

Provenance and Peer Review: This article was commissioned by the editorial office, Frontiers of Oral and Maxillofacial Medicine for the series "Diagnosis and Treatment of Periorbital Basal Cell Carcinoma". The article has undergone external peer review.

Peer Review File: Available at https://fomm.amegroups.com/ article/view/10.21037/fomm-21-11/prf

Conflicts of Interest: All authors have completed the ICMJE uniform disclosure form (available at https://fomm. amegroups.com/article/view/10.21037/fomm-21-11/coif). The series "Diagnosis and Treatment of Periorbital Basal Cell Carcinoma" was commissioned by the editorial office without any funding or sponsorship. LMH and VK served as the unpaid Guest Editors of the series. LMH serves as an unpaid editorial board member of Frontiers of Oral and Maxillofacial Medicine from Sep 2020 to Aug 2022. The authors have no other conflicts of interest to declare.

Ethical Statement: The authors are accountable for all aspects of the work in ensuring that questions related to the accuracy or integrity of any part of the work are appropriately investigated and resolved.

Open Access Statement: This is an Open Access article distributed in accordance with the Creative Commons Attribution-NonCommercial-NoDerivs 4.0 International License (CC BY-NC-ND 4.0), which permits the noncommercial replication and distribution of the article with the strict proviso that no changes or edits are made and the original work is properly cited (including links to both the formal publication through the relevant DOI and the license). See: https://creativecommons.org/licenses/by-nc-nd/4.0/.

\section{References}

1. Kakkassery V, Loeffler KU, Sand M, et al. Current diagnostics and therapy recommendations for ocular basal cell carcinoma. Ophthalmologe 2017;114:224-36.

2. Weiling M, Bergua A, Kruse FE, et al. Therapy options for malignant eyelid tumors. Ophthalmologe 2016;113:1095-108.

3. Lang BM, Balermpas P, Bauer A, et al. S2k Guidelines for Cutaneous Basal Cell Carcinoma - Part 1: Epidemiology, Genetics and Diagnosis. J Dtsch Dermatol Ges 2019;17:94-103.

4. Rokohl AC, Löser H, Mor JM, et al. Young male patient with unusual space-occupying lesion of the lower eyelid. Ophthalmologe 2020;117:73-7.

5. Rokohl AC, Kopecky A, Guo Y, et al. Surgical resection with ophthalmoplastic reconstruction: Gold standard in periocular basal cell carcinoma. Ophthalmologe 2020;117:95-105.

6. Rokohl AC, Koch KR, Mor JM, et al. Personalized medicine in the treatment of periocular tumors: Targeted treatment and use of immune checkpoint inhibitors. Ophthalmologe 2020;117:521-7. 
7. Kakkassery V, Heindl LM. SOP - Standarized procedures in diagnostics and therapies of periocular basal cell carcinoma. Klin Monbl Augenheilkd 2017. [Epub ahead of print].

8. Hou X, Rokohl AC, Ortmann M, et al. Effective treatment of locally advanced periocular basal cell carcinoma with oral hedgehog pathway inhibitor? Graefes Arch Clin Exp Ophthalmol 2020;258:2335-7.

9. Kakkassery V, Emmert S, Adamietz IA, et al. Alternative treatment options for periorbital basal cell carcinoma. Ophthalmologe 2020;117:113-23.

10. Kakkassery V, Heindl LM. Standard operation procedure in periorbital basal cell carcinoma. Ophthalmologe 2020;117:124.

11. Lang BM, Balermpas P, Bauer A, et al. S2k Guidelines for Cutaneous Basal Cell Carcinoma - Part 2: Treatment, Prevention and Follow-up. J Dtsch Dermatol Ges 2019;17:214-30.

12. Lauterbach B, Kakkassery V, Debus D, et al. Advanced periocular basal cell carcinoma-a therapeutic challenge. Ophthalmologe 2019;116:273-7.

13. Kopecky A, Rokohl AC, Heindl LM. Techniques for the Reconstruction of the Posterior Eyelid Lamella. Klin Monbl Augenheilkd 2018;235:1415-28.

14. Auw-Haedrich C, Frick S, Boehringer D, et al. Histologic safety margin in basal cell carcinoma of the eyelid: correlation with recurrence rate. Ophthalmology 2009;116:802-6.

15. Zimmermann AC, Klauss V. Predictors of recurrent basalioma of the eyelids and periorbital region. Ophthalmologe 2001;98:555-9.

16. Hauschild A, Breuninger H, Kaufmann R, et al. Brief S2k guidelines--Basal cell carcinoma of the skin. J Dtsch Dermatol Ges 2013;11 Suppl 3:10-5, 1-6.

17. Kopecky A, Koch KR, Bucher F, et al. Results of Cutler-

doi: $10.21037 /$ fomm-21-11

Cite this article as: Rokohl AC, Kopecky A, Wawer Matos PA, Guo Y, Kakkassery V, Heindl LM. Complex techniques of eyelid reconstruction following extensive basal cell carcinoma resection. Front Oral Maxillofac Med 2021;3:18.
Beard procedure for reconstruction of extensive full thickness upper eyelid defects following tumor resection. Ophthalmologe 2016;113:309-13.

18. Lipke KJ. Possibilities in the surgical management of eyelid trauma. HNO 2011;59:783-90.

19. Levin M. Manual of Oculoplastic Surgery. 4th ed. USA: Elsevier, 2010.

20. Stafanous SN. The switch flap in eyelid reconstruction. Orbit 2007;26:255-62.

21. Uemura T, Yanai T, Yasuta M, et al. Switch Flap for Upper Eyelid Reconstruction-How Soon Should the Flap Be Divided? Plast Reconstr Surg Glob Open 2016;4:e695.

22. Hishmi AM, Koch KR, Matthaei M, et al. Modified Hughes procedure for reconstruction of large fullthickness lower eyelid defects following tumor resection. Eur J Med Res 2016;21:27.

23. Eusterholz T, Wenzel M. Eyelid reconstruction with tarsomarginal transplant. Ophthalmologe 1997;94:745-50.

24. Timm A, Vick HP, Guthoff R. Glabellar transposition flap for medial canthal reconstruction after tumour excision. Klin Monbl Augenheilkd 2002;219:740-4.

25. Custer PL. Trans-nasal flap for medial canthal reconstruction. Ophthalmic Surg 1994;25:601-3.

26. Moretti EA, Gomez Garcia F. Myocutaneous flap (V-Y design) from the nasal bridge for medial canthal reconstruction. Ophthalmic Plast Reconstr Surg 1998;14:298-301.

27. Rokohl AC, Mor JM, Trester M, et al. Rehabilitation of Anophthalmic Patients with Prosthetic Eyes in Germany Today - Supply Possibilities, Daily Use, Complications and Psychological Aspects. Klin Monbl Augenheilkd 2019;236:54-62.

28. Rokohl AC, Koch KR, Kabbasch C, et al. Importance of interdisciplinary collaboration for optimal treatment of orbital tumors. HNO 2019;67:528-33. 